\title{
SUBSTANCE P-CONTAINING PATHWAYS TO AVIAN SYMPATHETIC PREGANGLIONIC NEURONS: EVIDENCE FOR MAJOR SPINAL-SPINAL CIRCUITRY ${ }^{1}$
}

\author{
BRIAN M. DAVIS AND JOHN B. CABOT ${ }^{2}$ \\ Department of Neurobiology and Behavior, State University of New York at Stony Brook, Stony Brook, New York 11794
}

Received October 31, 1983; Revised January 12, 1984; Accepted February 1, 1984

\begin{abstract}
The origin of substance P-like immunoreactivity (SPLI) in the neuropil of sympathetic preganglionic neurons (SPNs) was investigated in pigeon (Columba livia). Previous investigators had suggested that a major SPLI-containing projection to SPNs arose from caudal brainstem (Johansson, O., T. Hokfelt, B. Pernow, S. L. Jeffcoate, N. White, H. W. M. Steinbusch, A. A. J. Verhofstad, P. C. Emson, and E. Spindel (1981) Neuroscience 6: 1857-1881; Gilbert, R. F. T., P. C. Emson, S. P. Hunt, G. W. Bennett, C. A. Marsden, B. E. B. Sandberg, H. W. M. Steinbusch, and A. A. J. Verhofstad (1982) Neuroscience 7: 69-87; Helke, C. J., J. J. Neil, V. J. Massari, and A. D. Loewy (1982) Brain Res. 243: 147 152) and, furthermore, that the bulbospinal fibers and terminals in the SPN neuropil which contained SPLI also contained serotonin-like immunoreactivity (5-HTLI) (Johansson, O., T. Hokfelt, B. Pernow, S. L. Jeffcoate, N. White, H. W. M. Steinbusch, A. A. J. Verhofstad, P. C. Emson, and E. Spindel (1981) Neuroscience 6: 1857-1881; Gilbert, R. F. T., P. C. Emson, S. P. Hunt, G. W. Bennett, C. A. Marsden, B. E. B. Sandberg, H. W. M. Steinbusch, and A. A. J. Verhofstad (1982) Neuroscience 7: 69-87). In the present study, various spinal lesions were made and the SPLI and 5HTLI content of thoracic spinal cord was examined using immunohistochemistry.

Interruption of descending bulbospinal fibers by cervical hemisection had no demonstrable effect on SPLI in the SPN neuropil, while 5-HTLI was almost totally depleted in the half of the spinal gray (including the SPN cell column) ipsilateral to the hemisection. Following a complete thoracic transection, SPLI was only depleted 2 to $3 \mathrm{~mm}$ rostral and caudal to the lesion, while normal SPLI staining was present in the remainder of the spinal cord. 5-HTLI was totally depleted caudal to a thoracic transection. Dorsal rhizotomy of three to six sequential spinal segments significantly depleted SPLI in the dorsal horn but had no effect on SPLI in the region of SPNs. Major depletion of SPLI within the SPN cell column was only seen when portions of thoracic spinal cord were isolated by complete transections or unilateral hemisections. Finally, evidence was found for intraspinal SPLI-containing fiber systems. These results demonstrate that the majority of SPLI in the SPN cell column in the pigeon is probably of intraspinal origin. The data also confirm that 5-HTLI is contained in axons and terminals arising from cell bodies of supraspinal origin.
\end{abstract}

The anatomical and neurochemical identification of intraspinal and bulbospinal pathways with monosynaptic inputs on sympathetic preganglionic neurons (SPNs) is a longstanding fundamental problem (Reis, 1972; Loewy and Neil, 1981; Cabot et al., 1982; 1983). With the exception of histofluorescence observations (Carlsson et al., 1964; Dahlstrom and Fuxe, 1964, 1965), earlier attempts met with little success due to inherent technical limitations. Within the last 8 years, however, several "chemically identifiable" direct bulbospinal-SPN pathways have been convincingly demonstrated. These include probable

\footnotetext{
${ }^{1}$ We are greatly indebted to Mrs. Carol Hall for help with the histology presented here. We would also like to thank Noah Bogan and Drs. Jon T. Erichsen and Kent T. Keyser for valuable suggestions on experimental procedure and the manuscript. This work was supported in part by Grant HL24103 (J. B. C.) from the National Heart, Lung and Blood Institute.

${ }^{2}$ To whom correspondence should be addressed.
}

serotonin $(5-\mathrm{HT})$-containing inputs from the subnuclei of the medullary/caudal pontine raphe complex (Loewy and McKellar, 1981; Cabot and Bogan, 1982; Cabot et al., 1982; Gilbert et al., 1982; Helke et al., 1982), a norepinephrine-containing projection arising from the A5 cell group in ventrolateral pons (Loewy et al., 1979; Loewy and Neil, 1981), an epinephrinecontaining projection from ventrolateral medulla (Ross et al., 1981), and an oxytocin-containing (mesotocin in birds) pathway from the paraventricular nucleus of the hypothalamus (Saper et al., 1976; Swanson, 1977; Nilaver et al., 1980; Cabot et al., 1982). Additional direct projections to SPNs from the dorsolateral pons have also been described, but chemical identification of the putative neurotransmitters for these pathways is still controversial (Loewy et al., 1979; Westlund and Coulter, 1980; Martin et al., 1981).

The successful application of immunohistochemical methods for the visualization of neuropeptides in central nervous system (CNS) has provided a basis for expanding the characterization 
of other peptidergic pathways providing direct inputs onto SPNs. In particular, there is evidence in several vertebrates that the undecapeptide substance $\mathrm{P}$ (SP) is present within the SPN neuropil (e.g., rat, Ljungdahl et al., 1978; opossum, Ditirro et al., 1981; human, de Lanerolle and LaMotte, 1982). The location(s) of the cells giving rise to this dense terminal projection is unknown, although it has been suggested that neurons within the medullary/caudal pontine raphe complex might be involved (Johansson et al., 1981; Gilbert et al., 1982; Helke et al., 1982. Anterograde and retrograde data have also implicated this midline caudal brainstem region as the source of $5-\mathrm{HT}$ input to the SPNs (Loewy and McKellar, 1981; Loewy and Neil, 1981; Cabot et al., 1982). In addition, Chan-Palay and coworkers (Chan-Palay et al., 1978; Chan-Palay, 1979) have provided further evidence establishing that 5 -HT and SP coexist within some rat raphe neurons. Studies by Bowker et al. (1981) have shown that some of these medullary SP/5-HT neurons project to the spinal cord. Moreover, recent observations by Gilbert et al. (1982) indicate that the destruction of 5HT-containing raphe neurons results in the partial loss of SP terminations within the rat SPN neuropil. The combined data strongly support the hypothesis that neurons within the caudal raphe complex co-transport both $\mathrm{SP}$ and $5-\mathrm{HT}$ to terminals within the SPN cell column. However, Helke and co-workers (1982) have shown that in rat, destruction of medullary 5-HT neurons is not accompanied by diminution of SP in the SPN neuropil.

The present study was initiated to determine generally the location of the cells or origin of the dense SP terminal field within the SPN cell column of the pigeon (Columba livia). The investigations included an assessment of possible relative contributions from dorsal root ganglion cells, spinal interneurons, and bulbospinal projection neurons.

\section{Materials and Methods}

Experimental animals. Experiments were performed on white Carneaux pigeons (C. livia), 2 to 6 months old ( 400 to $600 \mathrm{gm}$ ), which were obtained from Palmetto Pigeon Plant (Sumter, SC).

General procedures. Pigeons were anesthetized with $0.3 \mathrm{ml}$ of pentobarbital $(0.64 \mathrm{mg} / \mathrm{ml})$ administered intramuscularly. All animals were intubated, respirated, and immobilized with $0.2 \mathrm{ml}$ of pancuronium bromide $(1 \mathrm{mg} / \mathrm{ml}$, i.m.). Spinal lesions were made with a knife needle, and microcautery was employed as needed to minimize bleeding. 'I'hree possible sites of origin of the SP-containing fibers were considered: the dorsal root ganglia, the brainstem, and the spinal cord. Accordingly, the experiments were grouped into three categories: (1) examination of the sensory pathways to the SPNs, (2) determination of bulbospinal contributions, and (3) characterization of intraspinal contributions.

SPLI-containing projections from dorsal root ganglion. Two series of experiments were performed. In the first, birds received three, five or six sequential, unilateral dorsal rhizotomies (Tl to $\mathrm{T} 3, \mathrm{C} 11$ to $\mathrm{T} 1$, and C12 to T3, respectively; terminology according to Huber, 1936). Following a 1- to 2-week survival time, the animals were perfused and the cervical, thoracic, and upper lumbar spinal cord were processed and examined for the presence of SP-like and 5-HT-like immunoreactivity (SPLI and 5-HTLI, respectively; see below).

Determination of bulbospinal SPLI-containing projections. In this experimental group, pigeon spinal cord was hemisected or totally transected. Two animals received hemisecting lesions at high cervical levels (C3 to $\mathrm{C} 5$ ), while two others received hemisecting lesions at $\mathrm{T} 1$. In addition, two birds had their spinal cords totally transected at either T3 or T5. Survival time was 7 or 14 days, after which birds were perfused and thoracic spinal segments were removed and processed for SPLI and 5-HTLI (see below). The spinal segment which contained the hemisection was removed, embedded in paraffin, and cut transversely $(15 \mu \mathrm{m})$ on à rotary microtome. The extent of each lesion was assessed by making camera lucida drawings of Kluver-Barrera (1953)stained sections. Seven- and 14-day survival times were judged to be adequate because previous investigators have shown, using radioimmunoassay, $70 \%$ depletion of SP in the rat spinal cord 7 days after cervical hemisection (Kanazawa et al., 1979). Furthermore, time course studies of SP depletion in lumbar and cervical spinal cord following brainstem lesion produced by neurotoxins show that near maximum depletion is seen by day 3 (Gilbert et al., 1982). Immunohistochemical studies have also reported rapid depletion (4 days) of SPLI in the spinal cord following dorsal root section (Tessler et al., 1980).

Determination of intraspinal SPLI-containing projections. In the final group of six birds, lesions were placed above and below a spinal segment so as to isolate a portion of the spinal cord from ascending and descending pathways. Two birds received paired spinal hemisections that isolated T3. Two other birds were hemisected at 5 and 14 days later received two additional hemisections (ipsilateral to the C5 lesion) at $\mathrm{T} 2$ and $\mathrm{T} 4$. In one bird, the spinal cord was completely transected above the dorsal root ganglion at T3 and below the ganglion at T5. In one other bird, the spinal cord between $\mathrm{T} 3$ and $\mathrm{T} 4$ was isolated by complete transections above the dorsal root ganglion at T3 and below the dorsal root ganglion at T5. Survival time for all lesioned birds was 7 days (for the birds hemisected at $\mathrm{C} 5$, the survival time was 7 days after the thoracic lesions), after which they were perfused and the spinal cords were processed for the presence of SPLI and 5-HTLI (see below).

Immunohistochemical methods. All birds were deeply anesthetized with $0.7 \mathrm{ml}$ of sodium pentobarbital $(0.64 \mathrm{mg} / \mathrm{ml})$ and were perfused transcardially with $6 \%$ dextran in $0.1 \mathrm{M}$ phosphate buffer $(\mathrm{PB}, \mathrm{pH} 7.4)$ followed by 1 liter of a $4 \%$ paraformaldehyde solution containing $0.1 \mathrm{M}$ D,L-lysine $\mathrm{HCl}$ and $0.1 \mathrm{M}$ sodium periodate in $\mathrm{PB}$ (PLP; McLean and Nakane, 1974). Spinal cords were removed and fixed for an additional 2 to $6 \mathrm{hr}$ in the same fixative at $4^{\circ} \mathrm{C}$, transferred to a fresh solution of $20 \%$ sucrose $\mathrm{PB}$, and stored overnight at $4^{\circ} \mathrm{C}$. Frozen serial $40-\mu \mathrm{m}$ sections were cut in the transverse plane, collected in staining dishes, and washed (three times, $10 \mathrm{~min} /$ wash in $\mathrm{PR}$ ) at room temperature.

Sections were then incubated for 24 to $36 \mathrm{hr}$ at $4^{\circ} \mathrm{C}$ in either a monoclonal SP antibody raised in rat (provided by A. C. Cuello), a serum 5-HT antibody raised in rabbit (ImmunoNuclear), or a serum SP antibody raised in rabbit (provided by I. Black and J. Kessler). Antisera were diluted $1: 1000$ and 1:500, respectively, in PB containing $0.3 \%$ Triton X-100. After incubation, sections were returned to staining dishes, washed (three times, $10 \mathrm{~min} /$ wash in PB), and processed using the peroxidase-antiperoxidase (PAP) method of Sternberger (1979). Tissue stained for SPLI was incubated in goat anti-rat or goat antirabbit IgG (Miles-Yeda) at a 1:100 dilution for 30 to $45 \mathrm{~min}$ at room temperature. Following washes (three times, $10 \mathrm{~min} /$ wash in $\mathrm{PB}$ ), sections were placed in rat or rabbit PAP (Sternberger, Dako) at a 1:100 dilution for 30 to $45 \mathrm{~min}$ at room temperature. Sections were again washed (three times, $10 \mathrm{~min} /$ wash in $\mathrm{PB}$ ) and then placed in a solution of $3,3^{\prime}$-diaminobenzidene tetrahydrochloride $(100 \mathrm{mg} / 100 \mathrm{ml})$ in $0.05 \mathrm{M}$ Tris ( $\mathrm{pH} 7.2$ ) for a 20 -min pre-incubation period, followed by an additional 10-min incubation upon the addition of hydrogen peroxide (final concentration of $0.01 \%$ ). Tissue was washed in five to six changes of fresh PB ( 2 to 5 min each), mounted on gelatin-coated slides, dehydrated, cleared in xylene, and coverslipped. Some slides were counterstained with neutral red or cresylecht violet.

Tissue stained for 5-HTLI was processed exactly the same as outlined above, but goat anti-rabbit IgG (Miles-Yeda) and rabbit PAP (Dako) were used.

Preadsorption control procedures were performed in which the primary antibodies were incubated with the appropriate synthetic antigen before being used in immunostaining procedures. Anti-SP antibodies were preadsorhed with synthetic SP $(50 \mu \mathrm{M})$ (Pennisula) at $4^{\circ} \mathrm{C}$ for 24 $\mathrm{hr}$. Preadsorption treatment of the SP antisera with synthetic SP totally abolished SPLI.

Recent evidence indicates that 5-HT antisera, like the one used in the present experiments, are actually specific for 6 -methoxy-tetrahydro- $\beta$-carboline (OH-THBC; Schipper and Tilders, 1983), a condensation product of $5-\mathrm{HT}$ and formalin (the BSA $/ 5-\mathrm{HT}$ conjugate used to immunize antibody-producing animals is the product of a condensation reaction employing formalin). Therefore, 5 -HT conjugated to BSA with formalin was used in the preadsorption experiments for the 5-HT antibody. 5-HTLI was totally abolished by incubation with the $5-\mathrm{HT} /$ BSA conjugate $(80 \mu \mathrm{g} / \mathrm{ml})$ at $4^{\circ} \mathrm{C}$ for $24 \mathrm{hr}$.

\section{Results}

Technical considerations. Due to the limitations of the immunohistochemical procedures, it is not possible to conclude definitively that the observed staining patterns are exclusively due to the presence of undecapeptide SP. It is possible that all 
or portions of the staining could result from the presence of larger precursor molecules that contain SP within their amino acid sequences or to metabolic breakdown products of SP itself. Agents structurally similar to SP are also occasionally sources of false positives. Two different anti-SP antisera were used in order to increase the probability of detecting nonspecific staining. Both antisera produced qualitatively the same results, and the staining produced by either of these antisera could be totally blocked by preadsorption with synthetic SP, suggesting that the majority of the observed staining must be due to SP. Finally, in experiments described elsewhere (McKelvy et al., 1982; B. M. Davis, J. E. Krause, J. B. Cabot, and J. F. McKelvy, manuscript in preparation), analysis by high performance liquid chromatography also indicates that pigeon SP is identical to synthetic SP. Nevertheless, because immunohistochemical techniques can produce "false positives" the use of "substance $\mathrm{P}$-like immunoreactivity" or "SP-positive staining" reflects the interpretation that the majority of the observed staining is due to SP. A similar line of reasoning follows for the use of the term "5-HT-like immunoreactivity" (see "Materials and Methods").

Normal distribution of SPLI and 5-HTLI in spinal cord. The normal pattern of SPLI observed in spinal segments C5, C13, $\mathrm{T} 1$, and $\mathrm{T} 5$ is shown in Figure 1 (terminology according to Huber, 1936). In all segments, intense SPLI fiber staining could be seen throughout laminae I and II of the dorsal horn (terminology according to Leonard and Cohen, 1975a). Laminae III and IV also contained SPLI staining throughout, but it appeared lighter and more diffuse than in lamina I or II. Fibrous staining could be seen in laminae VII and VIII, and this appeared to be continuous with SP-positive fibers in the lateral fasciculus (Fig. 1, $b$ and $e$ ). Light $\mathrm{SP}$-positive staining was also present throughout ventral horn laminae. The amount of SP staining in lamina IX varied with the density of motoneurons, such that appreciable amounts of SP were present in ventral horns of the motoneuron-rich brachial and lumbar enlargements (Fig. 1b). The SPLI around motoneurons was contained in numerous bouton-like swellings that appeared to cover the surface of motoncuron somata (Fig. 1c). This was in marked contrast to the pattern of 5-HTLI around motoneurons (see below). Lighter staining was observed in the ventral horns of midthoracic cord where fewer lamina IX motoneurons are found.

A major difference between cervical and thoracic spinal cord in the pattern of SPLI was found in the gray matter dorsal to the central canal. In upper and midcervical spinal segments, two thin bands of SPLI could be found dorsal to the central canal, oriented parallel to the dorsoventral axis of the spinal cord on either side of the midline. In low cervical (C14), thoracic, and high lumbar (L1) spinal cord, where SPNs are present, SPLI dorsal to the central canal expanded to form a sphere of immunoreactivity (Fig. 1, $d$ and e). (The sympathetic preganglionic cell column in pigeons is termed the column of Terni (Huber, 1936).) SPLI within the SPN neuropil was fibrous, with numerous punctate bouton-like swellings, and sometimes appeared to envelop cell bodies, often obscuring the borders of the preganglionic perikarya.

At all spinal levels examined, several regions of the white matter stained positively for SPLI. The tract of Lissauer and the superficial white matter that contains entering dorsal root fibers stained intensely for SP. Another densely staining fiber tract could be seen along the lateral border of the dorsal horn (arrows, Fig. 1e) where thick bundles of immunoreactive fibers were seen. Fine, lightly stained SPLI-positive fibers were also found in the dorsolateral quadrant.

Since 5-HTLI-containing fibers terminating in the spinal cord arise from cell bodies in the brainstem (Loewy and McKellar, 1981; Cabot and Bogan, 1982; Cabot et al., 1982; Gilbert et al., 1982; Helke et al., 1982), changes in 5-HTI I termination patterns following various lesions served as internal controls for examining differences in SPLI staining that might be due to interruption of bulbospinal pathways. The pattern of 5HTLI in the normal spinal cord was qualitatively similar in many respects to the pattern of SPLI (Fig. 2). In the dorsal horn, 5-HTLI staining was heaviest in laminae I and II, with light staining seen in laminae III and IV. Light 5-HTLI was observed in all intermediate and ventral horn laminae. Lamina IX 5-HTLI was distinctive with apparent dense "ringing" of motoneuron somata, especially in the motoneuron-rich brachial spinal cord (Fig. 2c). Some 5-HTLI staining was also seen in the region of the central canal, and, like the SPLI pattern, a major increase in densily coincided with the presence of SPNs (Fig. 2b). With respect to the white matter, a major difference between SPLI and 5-HTLI was the lack of 5-HTLI staining in the dorsal root entry zone and in the area immediately lateral to the dorsal horn. Immunoreactive fibers could be found in the dorsolateral, lateral, and superficial aspects of the ventral fasciculus. Overall, the 5-HTLI staining pattern appeared lighter than the SPLI pattern.

Effects of dorsal root rhizotomies on SPLI in spinal cord. These experiments were designed to determine whether a portion, or perhaps all, of the SPLI terminations within the SPN neuropil had cell bodies of origin within primary sensory spinal ganglia. Figure 3 illustrates a case where dorsal roots C14 to 'T4 were cut. SPLI staining in Lissauer's tract and in the superficially located dorsal rootlet entry zone was markedly diminished or absent throughout spinal segments C14 to T3 ipsilateral to the rhizotomies. Such depletion was not noticeable in C12 (midbrachial spinal cord). Significant depletion was observed in laminae I and II, and the SPLI was characteristically less dense. Within the spinal segments that were rhizotomized, greatest depletion occurred in spinal segments that had one or more dorsal rootlets cut rostral and caudal to that segment. For example, qualitatively more depletion was evident in $\mathrm{T} 2$ than in $\mathrm{T} 4$.

Effects of cervical hemisection and thoracic transection on SPLI and 5-HTLI in thoracic spinal cord. Hemisections of high cervical spinal cord (Fig. 4) did not significantly affect the pattern of SPLI in thoracic spinal cord (Fig. $5 a$ ). The only noticeable difference was the absence of fine SP-positive fibers in the dorsolateral fasciculus ipsilateral to the hemisection (Fig. 6). By comparison, there was a massive decrease in the 5-HTLI in the half of the thoracic spinal gray ipsilateral to the hemisection (Fig. $5 b$ ). Some light 5-HTLI labeling remained ipsilateral to the transection in the ventral horn and around the SPNs. Hemisections performed at T1 yielded similar results.

Total transections of the midthoracic spinal cord resulted in moderate depletion of SPLI staining in all portions of the spinal gray matter, rostral and caudal to the lesions (Fig. 7a), but only in tissue within one-half spinal segment ( 2 to $3 \mathrm{~mm}$ ) of the lesion. The SPLI in the fiber plexus immediately lateral to the dorsal horn also appeared depleted in the sections close to the transection. Examination of tissue more than one-half segment rostral and caudal to the lesion revealed apparently normal amounts of SPLI in all areas of the spinal gray (Fig. $7 b$ ). Such qualitative assessment is, at best, difficult but was aided by comparing the lesioned material to normal tissue from several unoperated birds processed concommitantly. A notable finding in the transected spinal cords was the appearance of swollen SPLI-positive fibers and granules bilaterally in the lateral and dorsolateral fasciculi near the lesion (arrows, Fig. $7 a$ ). These granules and fibers were seen both rostral and caudal to the lesion. Swollen fibers were also seen ipsilaterally, rostral and caudal to T1 hemisections. In comparison, 5-HTLI-positive staining was only seen rostral to the transection (Fig. 7c). Caudal to the transection almost total depletion of 5-HTLI was 

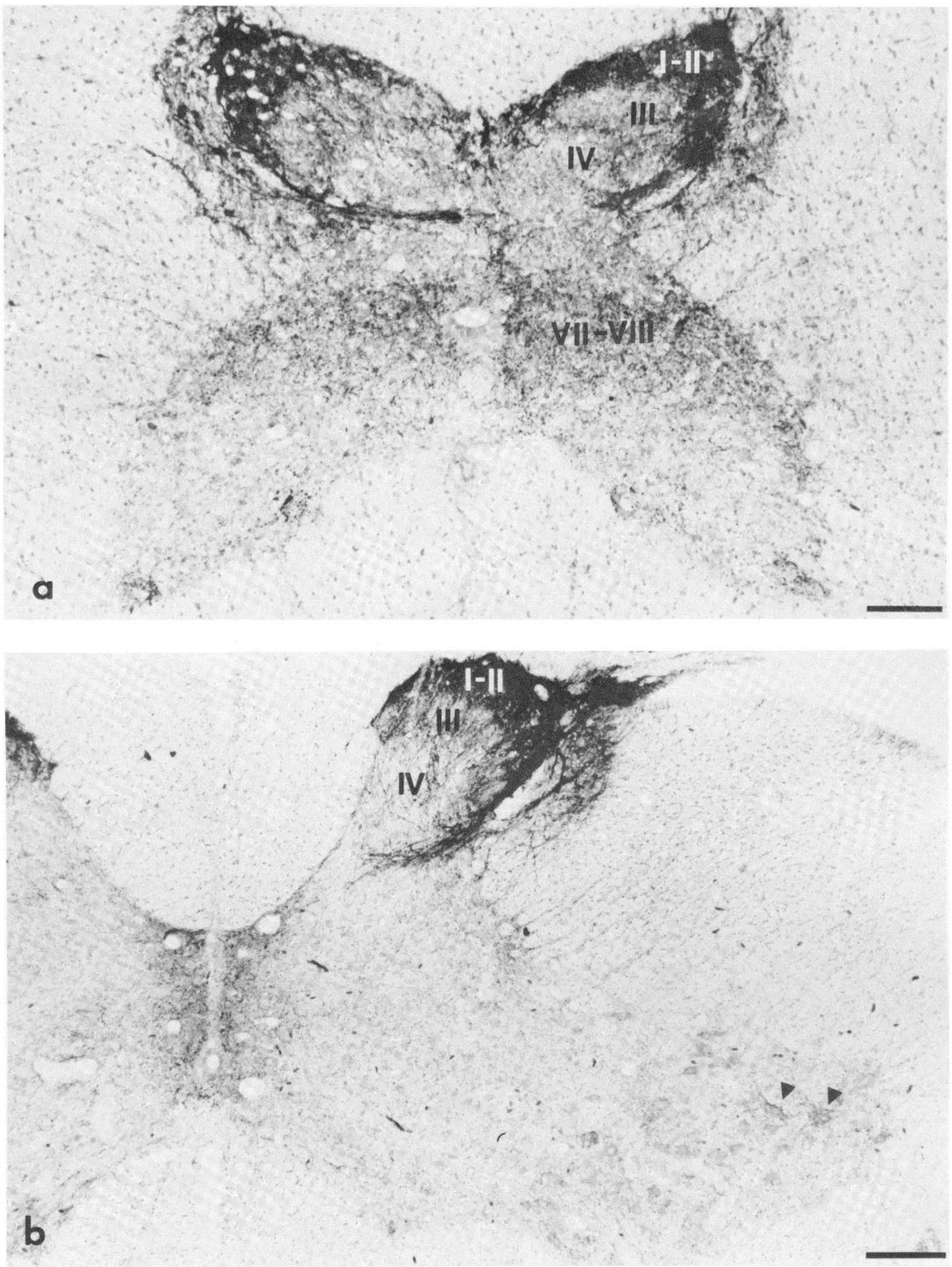
observed (Fig. 7d). It was also noted that the 5-HTLI staining appeared denser rostral to a transection compared to unlesioned animals. The above results were equivalent to those following transections at T3 or T5.

Spinal segment isolation. Significant depletion of SPLI in the SPN cell column as well as in the rest of the spinal gray matter was detectable in spinal cord segments that had been isolated by two hemisections or two complete transections (Fig. 8 ). Even in these cases, while the SPLI staining around the SPNs was reduced, it was never completely abolished. Despite overall depletion, appreciable staining also remained in the dorsal root entry zone, Lissauer's tract, and dorsal horn. Much of this staining presumably originates from primary afferent fibers and terminations arising from cells in the dorsal root ganglia attached to the isolated segments. SPLI staining patterns rostral and caudal to the isolated segment were similar to those seen rostral and caudal to a single transection; i.e., moderate depletion was seen near the lesions, whereas more normal staining was present at distances greater than one-half segment and farther from the transection. Again, swollen SPpositive fibers and granules were found in the lateral and dorsolateral fasciculus rostral and caudal to the isolated segment. Although carefully screened, none of the sections within the isolated segments were ever found to contain these SPpositive fibers and granules. These fibers and granules were also present in birds which received ipsilateral high cervical hemisections 7 days prior to the thoracic hemisections. The reason for preceding the thoracic hemisection with a high cervical hemisection was to destroy descending bulbospinal fibers that might contain SP. The appearance of SPLI-positive granules and fibers near a midthoracic lesion ipsilateral to a cervical hemisection indicates that the SP-positive fibers found near the lesions are probably not of bulbospinal origin.

Figure $8 b$ shows a section from a segment bracketed by two ipsilateral hemisections. SPLI staining is reduced in all portions of the section ipsilateral to the hemisections, including the SPN cell column. Only light staining remained in the SPN neuropil ipsilateral to the hemisections.

\section{Discussion}

Experiments were performed to determine the relative contribution of the dorsal root ganglia, brainstem, and spinal cord to the SPLI in the avian sympathetic preganglionic cell column. To establish this, the pattern of SPLI was examined following isolation of the thoracic spinal cord from supraspinal pathways, primary sensory neurons, and intraspinal circuits. The staining pattern of 5-HTLI was also examined because the great majority of spinal 5-HTLI is contained in bulbospinal axons (Loewy and McKellar, 1981; Cabot and Bogan, 1982; Cabot et al., 1982;

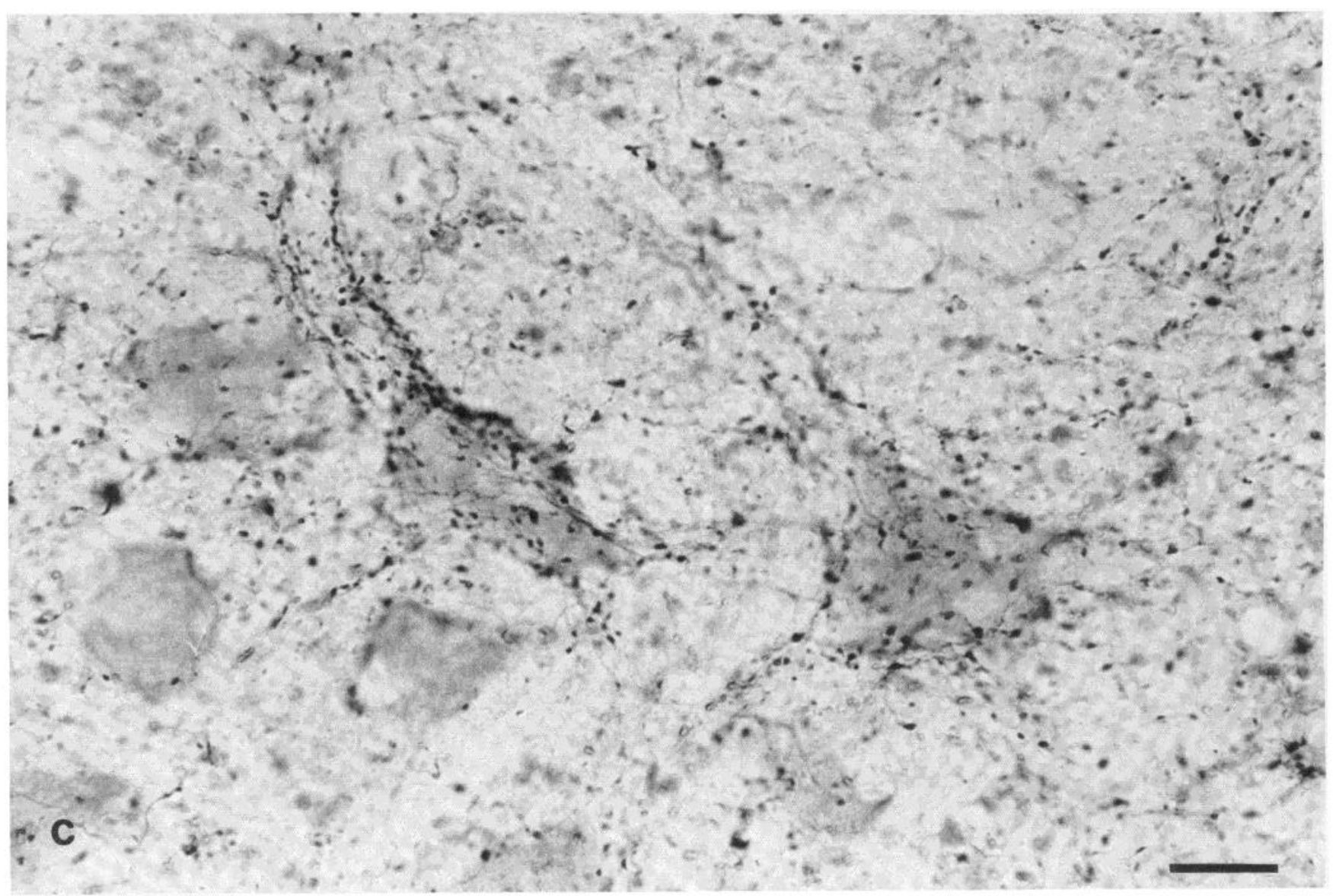

Figure 1c

Figure 1. Normal distribution of SPLI in spinal segments C5 (a), C13 (brachial enlargement) (b), T1 (d), and T3 (e). At all spinal levels, SPLI is densest in laminae I and II of the dorsal horn. Moderate SPLI is observed in laminae VII and VIII of C5 and T3 and dorsal to the central canal of $\mathrm{C} 13$. The arrows in $b$ indicate the ventral horn motoneurons shown in $c$. In $c$, many bouton-like SP-positive swellings can be seen surrounding the motoneuron somata. In $d$ and $e$, a disk of intense staining is present dorsal to the central canal in the column of Terni $(c T)$, the locus of SPNs. The double arrows in $e$ indicate the intraspinal SP-positive fiber tract (see the text). PAP method. Calibration bars $=$ $100 \mu \mathrm{m}$ for $a, b, d$, and $e ; 50 \mu \mathrm{m}$ for $c$ ). 

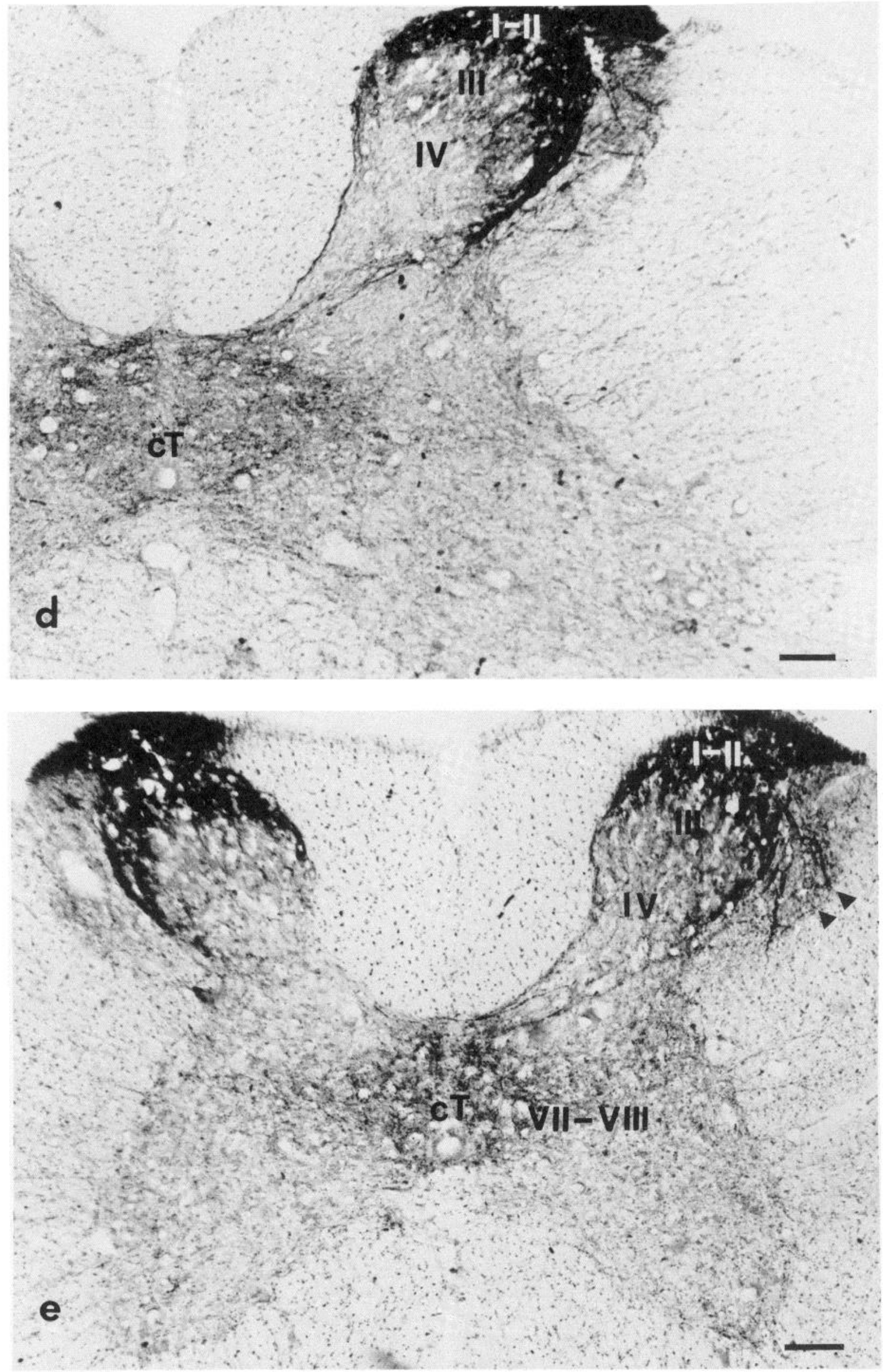

Figure 1, $d$ and $e$ 

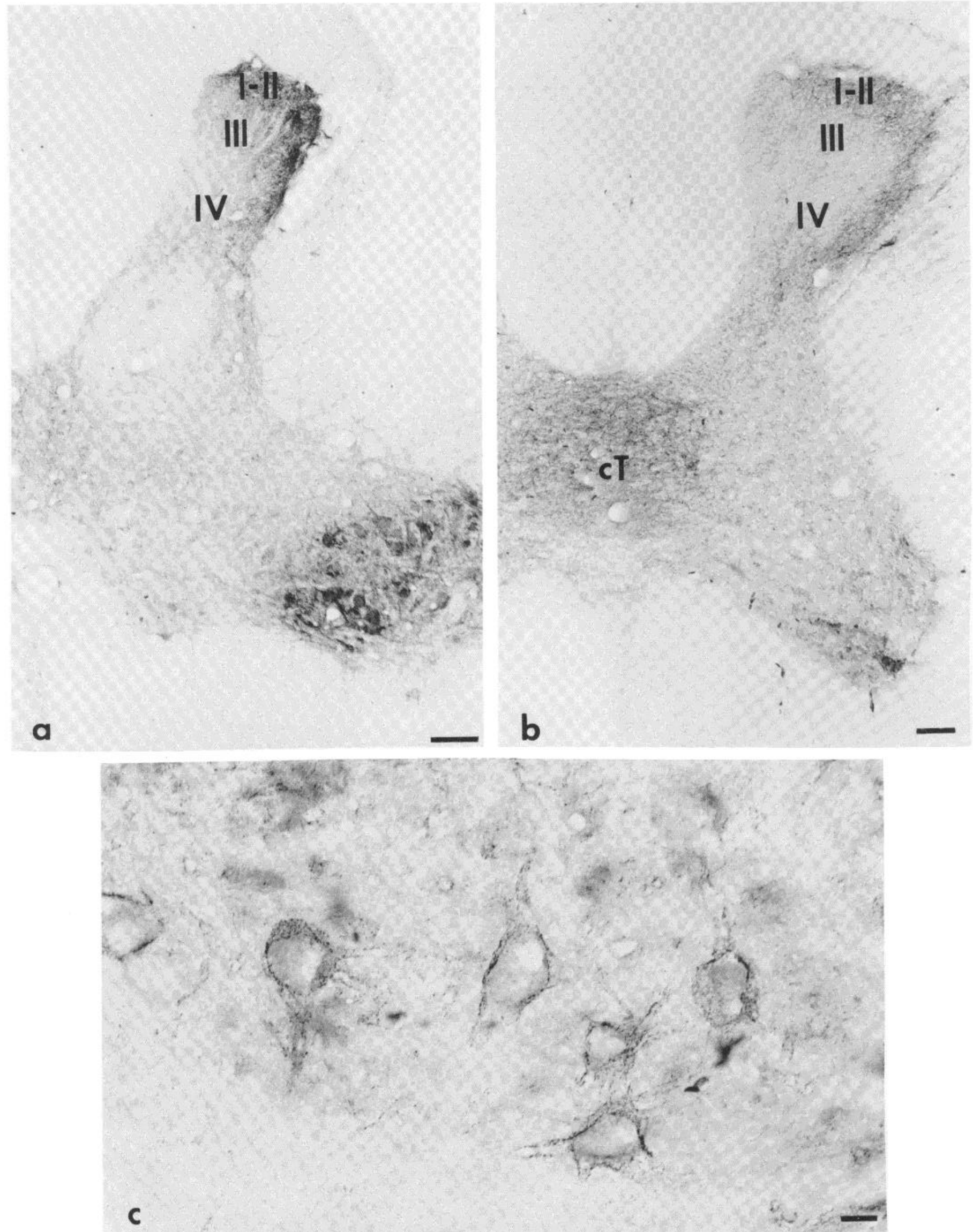

Figure 2. Normal distribution of 5-HTLI in spinal segments C13 (brachial enlargement) $(a)$ and T2 $(b)$. A high power photomicrograph of 5HTLI staining around motoneurons of the brachial enlargement is shown in $c$. At all spinal levels, moderate 5-HTLI staining is found in laminae I and II of the dorsal horn. Very light 5-HTLI is also observed in laminae III and IV and dorsal to the central canal in cervical segments. In the I and II of the dorsal horn. Very light 5-H staining is present dorsal to the central canal in the column of Terni $(c T)$, the locus of SPNs. In $c$, a dense ring of 5-HTLI can be seen around the perimeter of the somata. This pattern of immunoreactive staining is distinctly different from the a dense ring of 5-HTLI can be seen around the perimeter of the somata. This pattern of immunoreace of the motoneuron somata. PAP method. Calibration bars $=100 \mu \mathrm{m}$ for $a$ and $b ; 50 \mu \mathrm{m}$ for $c$. 


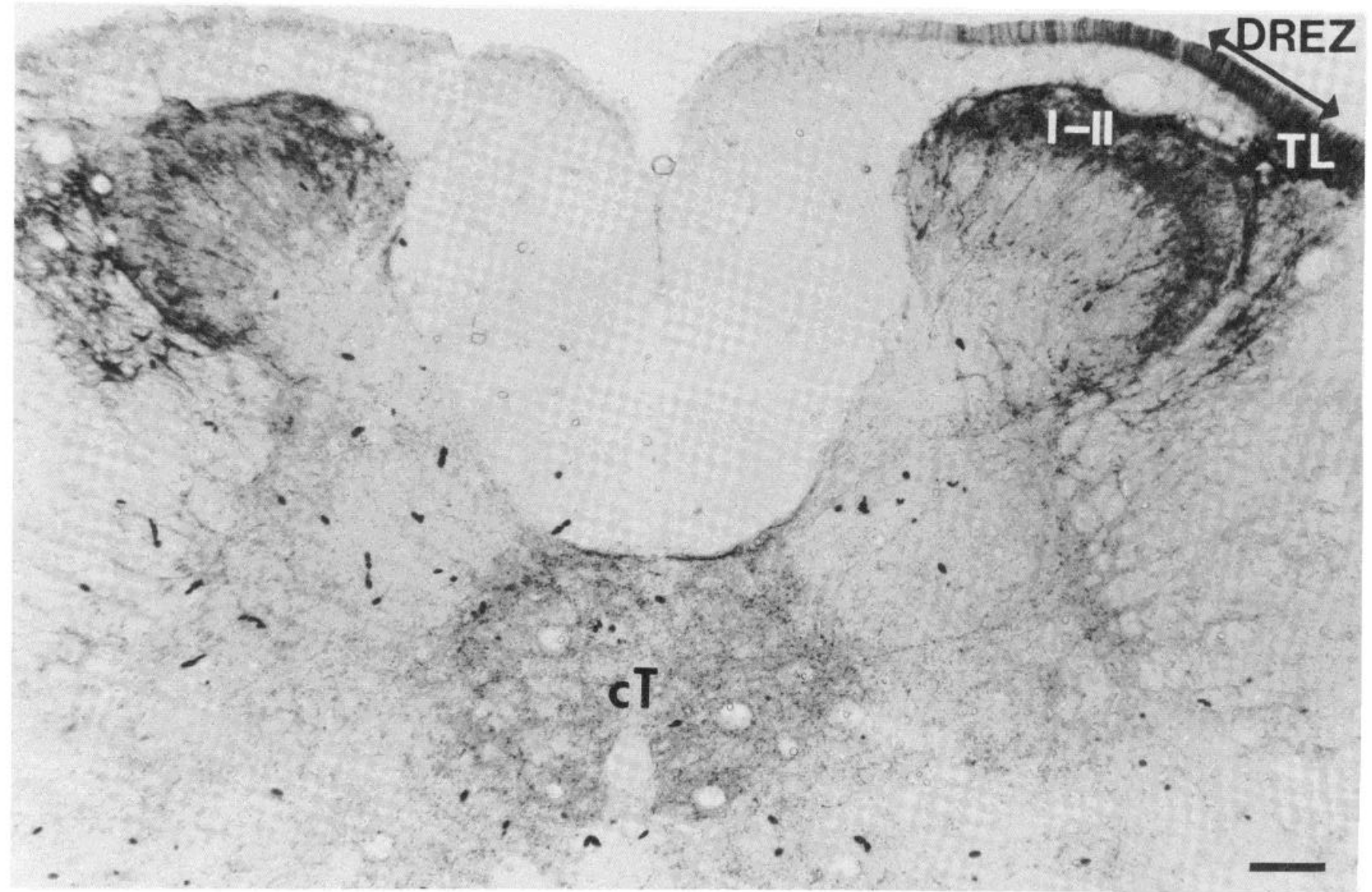

Figure 3. SPLI in T2 following section of left dorsal roots of spinal segments C14 to T4. In the region of the left dorsal horn, note the absence of SPLI staining in the dorsal root entry zone $(D R E Z)$ and the tract of Lissauer $(T L)$. Staining in laminae I and II is lighter and appears more diffuse. Staining in the column of Terni $(c T)$ appears normal. PAP method. Calibration bar $=100 \mu \mathrm{m}$.

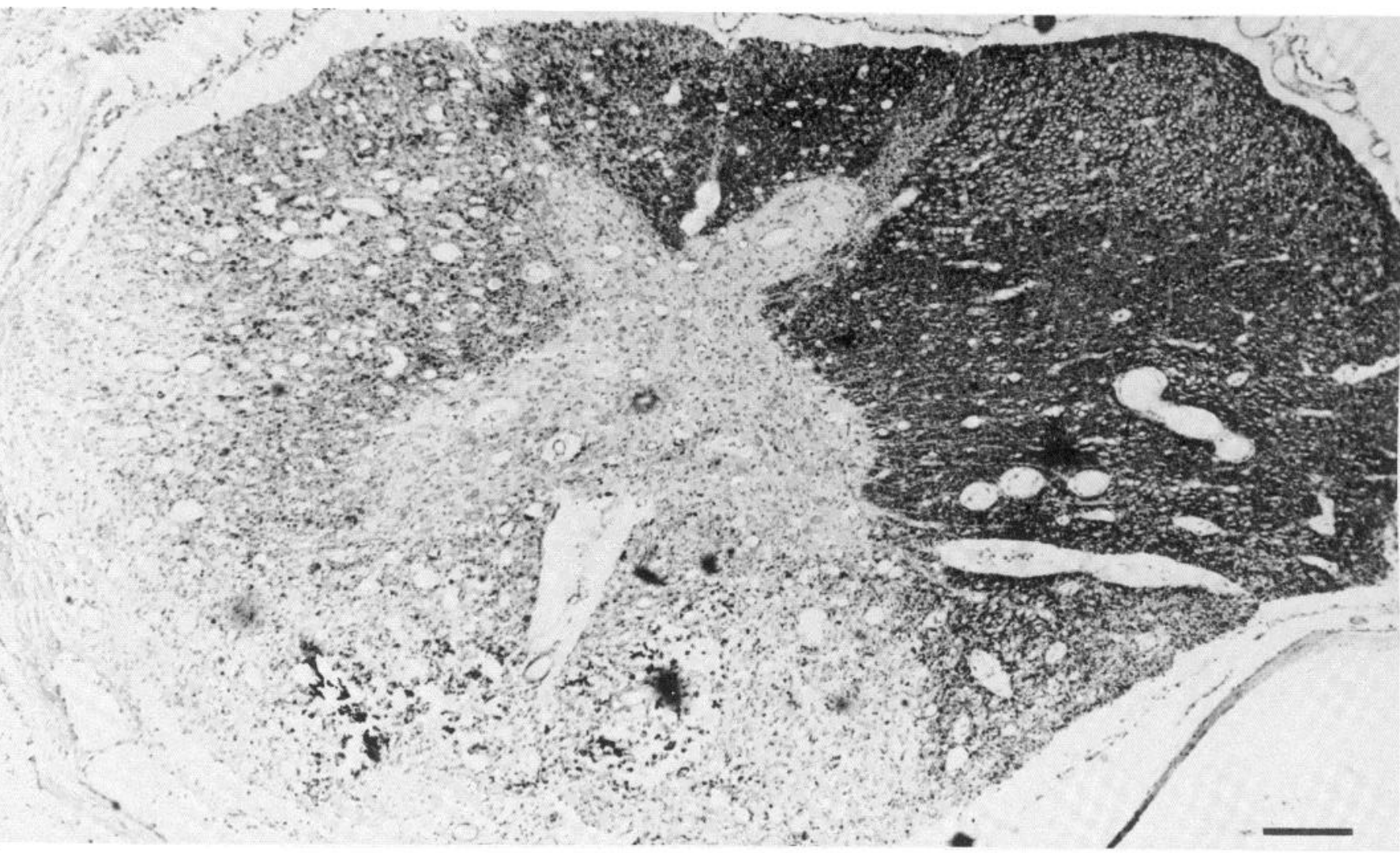

Figure 4. Kluver-Barrera-stained section of C5 showing the extent of a high cervical hemisection. The spinal cord from this case was stained for SPLI and 5-HTLI, and representative sections are shown in Figures 5 and 6. Dorsolateral, lateral, and ventrolateral fasciculi on the left side were destroyed, as were the right and left ventromedial fasciculi. The lesion also damaged the left half of dorsal columns. Calibration bar = $100 \mu \mathrm{m}$. 


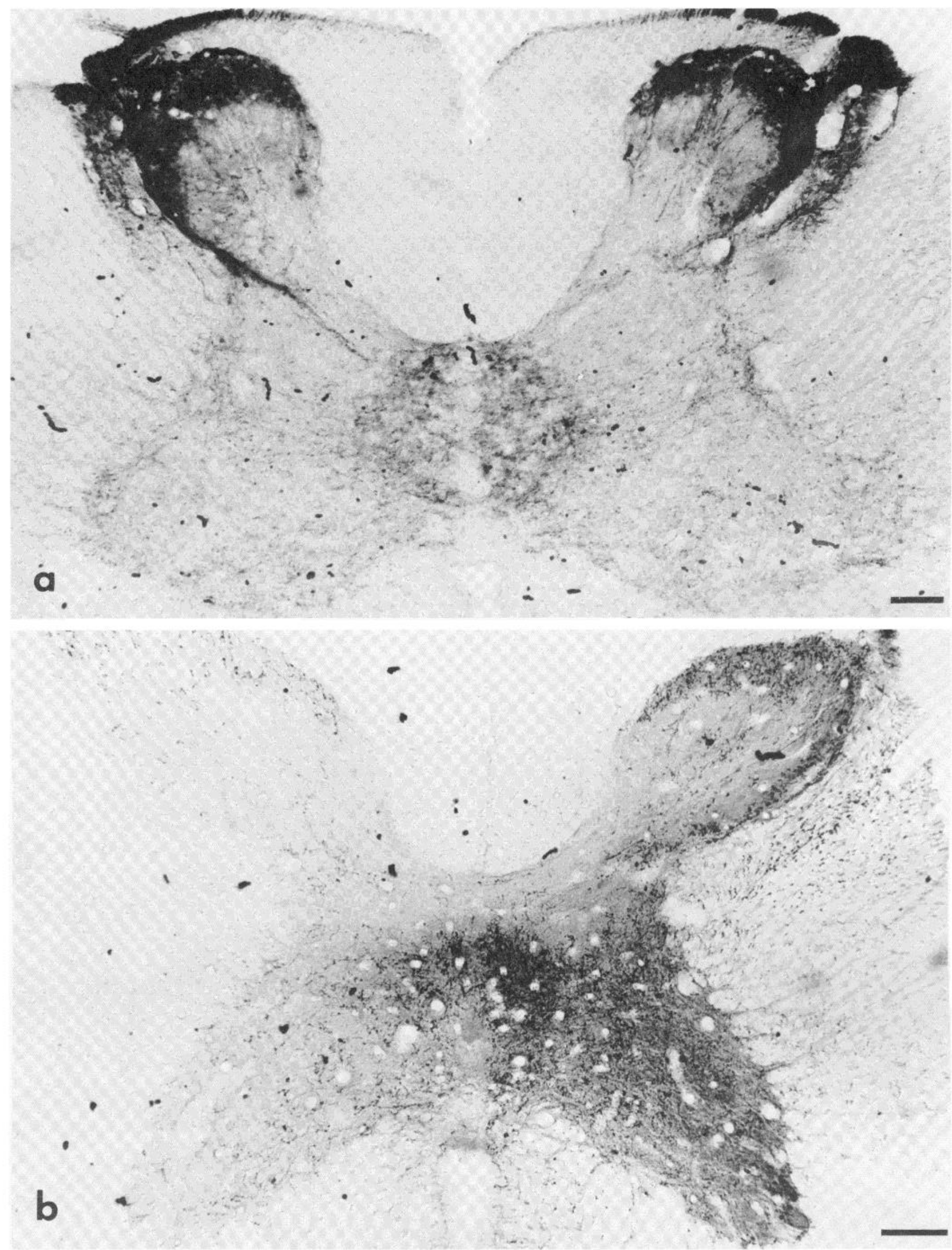

Figure 5. Effects of cervical hemisection (shown in Fig. 4) on SPLI and 5-HTLI staining in T1. $a$, SPLI in T1 appeared normal in all thoracic spinal segments except for the absence of fine SP-positive fibers in the lateral fasciculi ipsilateral to the lesion (see Fig. 6). $b$, 5-HTLI staining in T3 from same pigeon as $a$. 5-HTLI staining contralateral to the lesion (right side) appears slightly darker than in control animals but otherwise normal. Ipsilateral to the lesion, 5-HTLI staining is greatly diminished in all portions of the spinal gray, including the region of SPNs. PAP method. Calibration bars $=100 \mu \mathrm{m}$ for $a$ and $b$. 

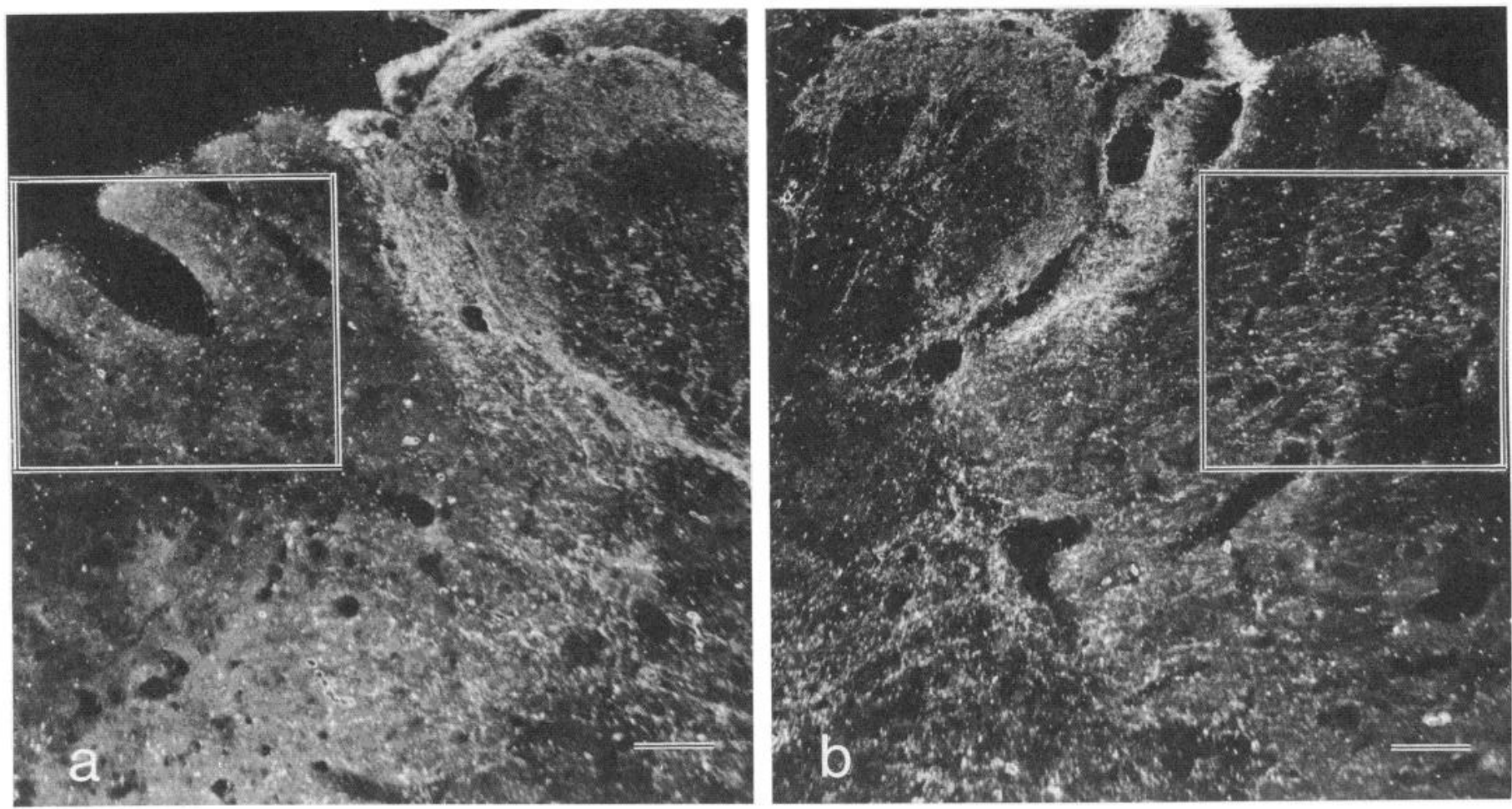

Figure 6. Darkfield photomicrograph of dorsolateral quadrant from the same section as shown in Figure 5a. $a$, Photomicrograph of dorsolateral quadrant ipsilateral to the hemisection. $b$, Photomicrograph of dorsolateral quadrant contralateral to the lesion. In $b$, fine SPLI-containing fibers can be seen in the dorsolateral quadrant $(b o x)$, while these are absent in the dorsolateral quadrant in $a$ (box). Loss of these fibers ipsilateral to the hemisection was the only apparent difference in the SPLI pattern following high cervical hemisection. Calibration bars $=100 \mu \mathrm{m}$.

Gilbert et al., 1982; Helke et al., 1982); thus, loss of 5-HTLI served as an indicator of the extent of disruption of descending brainstem systems.

Limitations of the PAP method for estimating depletion. It is important to point out that it is difficult to use the PAP method to make more than qualitative comparisons of tissue from different experimental animals. Numerous variables, such as the quality of perfusion and reagents, make it difficult to obtain equivalent staining in all cases. Consequently, antigen depletion can be easily detected only in circumstances in which there are large changes in antigen concentration. These caveats become especially important in experiments where the comparisons are being made between operated and unoperated animals (as opposed to, for example, comparisons of the spinal cord staining pattern ipsilateral and contralateral to a lesion where the unlesioned side can serve as an internal control). Therefore, it is not possible to be certain that lesions of the spinal cord (especially transection, where comparisions are made largely between operated and unoperated birds) have a negligible effect on SPLI in the SPN neuropil. However, radioimmunoassay experiments produce similar observations which confirm the above anatomical results (McKelvy et al., 1982; B. M. Davis, J. E. Krause, J. B. Cabot, and J. F. McKelvy, submitted for publication).

Brainstem SP-containing projections to SPNs. The mammalian brainstem contains several SP-positive cell groups (Ljungdahl et al., 1978; Ditirro et al., 1981; de Lanerolle and LaMotte, 1982). Of these, the caudal pontine/medullary raphe complex is proposed as an origin of SPLI-containing fibers which project to sympathetic preganglionic neurons (Johansson et al., 1981; Gilbert et al., 1982). In fact, several workers have found that some raphe SP-positive cells also contain 5-HT and have postulated that $5-\mathrm{HT}$ and SP are co-transported to the same terminal endings in the spinal cord (Chan-Palay et al., 1978; Chan-Palay, 1979; Bowker et al., 1981, 1982; Johansson et al., 1981; Gilbert et al., 1982).
In the pigeon, it was not possible to establish the existence of a major bulbospinal SP projection to the SPN cell column. Neither thoracic transection or high cervical or thoracic hemisections appeared to affect the levels of SPLI surrounding SPNs. However, these same manipulations dramatically reduced the amount to 5-HTLI in all portions of the spinal gray matter ipsilateral to the lesion, including the region of the SPNs. The weight of the combined data suggests strongly that the majority of SPLI in axons projecting to SPNs do not also contain 5-HT. Nevertheless, one particular observation renders it likely that SP projections from brainstem to spinal cord do exist in the pigeon. Specifically, fine SP-containing fibers normally found in the dorsolateral and lateral fasciculi were absent caudal to high cervical hemisections.

Dorsal root ganglion SP projections to thoracic spinal cord. Primary afferent neurons have been shown to contain SP and project to the dorsal horn (Hokfelt et al., 1975; Barber et al., 1979; Jessel et al., 1979; Tessler et al., 1980). Our results in pigeon are consistent with these previous observations, and the dorsal horn depletion seen following dorsal rootlet rhizotomy is qualitatively similar to that described by other investigators (Takahasi and Otsuka; 1975, Jessel et al., 1979). No evidence was found for SP-containing sensory projections to SPNs. The absence of such a projection was expected since electrophysiological and anatomical observations have never found evidence for a monosynaptic circuit between primary sensory neurons and SPNs despite careful investigations (e.g., Brooks, 1933, 1935; Beacham and Perl, 1964, 1965; Petras and Cummings, 1972; Leonard and Cohen, 1975b; Light and Perl, 1977, 1979). This finding was corroborated by the observation that following injection of $3 \mathrm{H}$-amino acids into dorsal root ganglia, the terminal fields did not include the preganglionic cell column (B. M. Davis and J. B. Cabot, unpublished observations). The autoradiographic pattern was equivalent to that reported previously using silver degeneration methods (Leonard and Cohen, $1975 \mathrm{~b})$. Thus, dorsal root ganglion neurons do not appear to be 

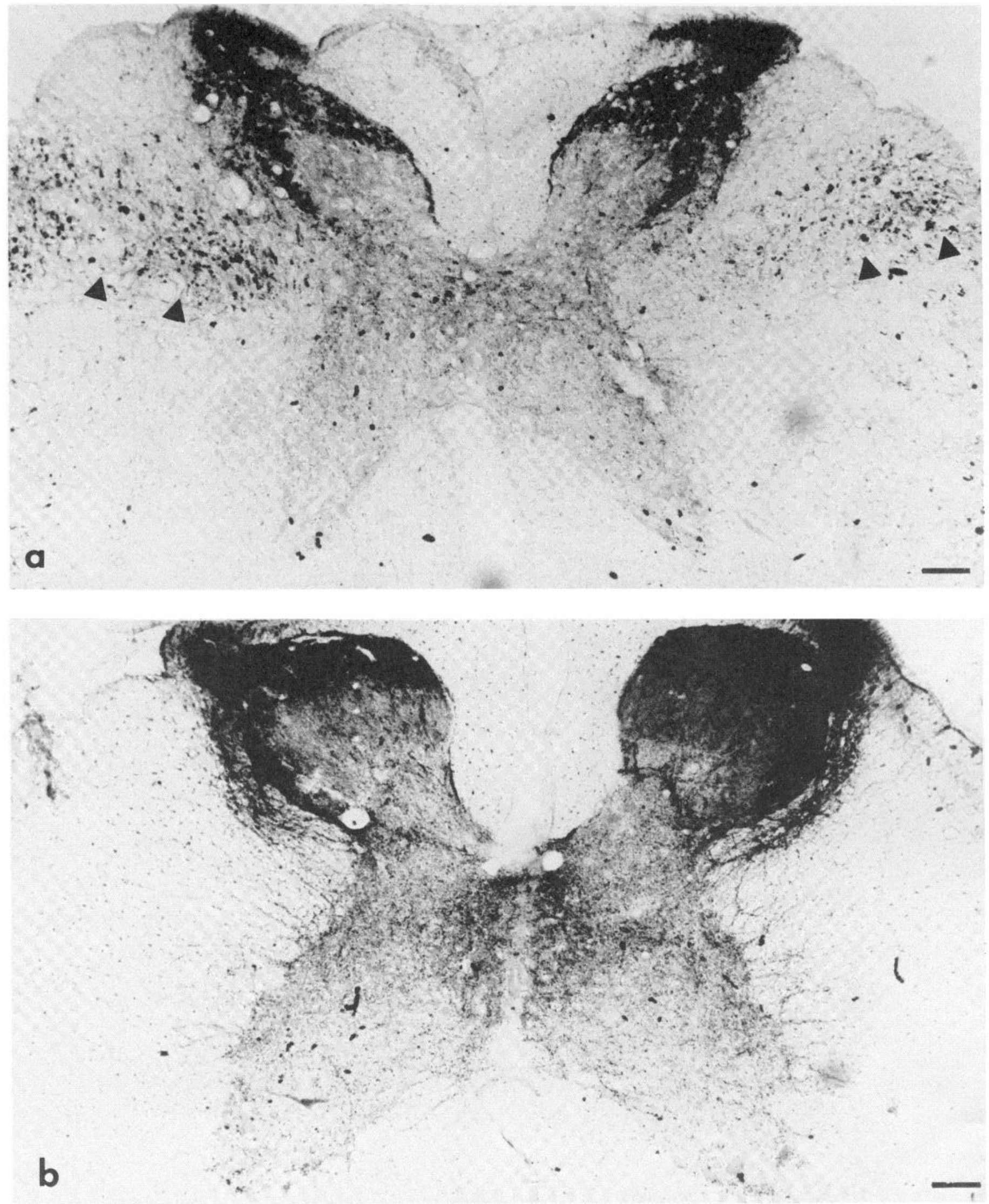

Figure 7. SPLI and 5-HTLI staining in thoracic spinal cord following T3 transection. $a$, SPLI in T3 immediately caudal to transection. SPLI is depleted in all laminae. Note SP-positive granules in the lateral fasciculi (arrows). $b$, SPLI in T4. SPLI appears normal in all laminae and in the SPN neuropil. $c, 5$-HTLI staining in the same case rostral to transection. Staining is slightly darker than in unoperated pigeons, and more fibers are visible in the intermediate laminae. $d, 5$-HTLI staining caudal to transection. 5-HTLI staining is almost totally depleted except for a few fragmented 5-HT-positive fibers in the right ventral horn. PAP method. Calibration bars $=100 \mu \mathrm{m}$. 

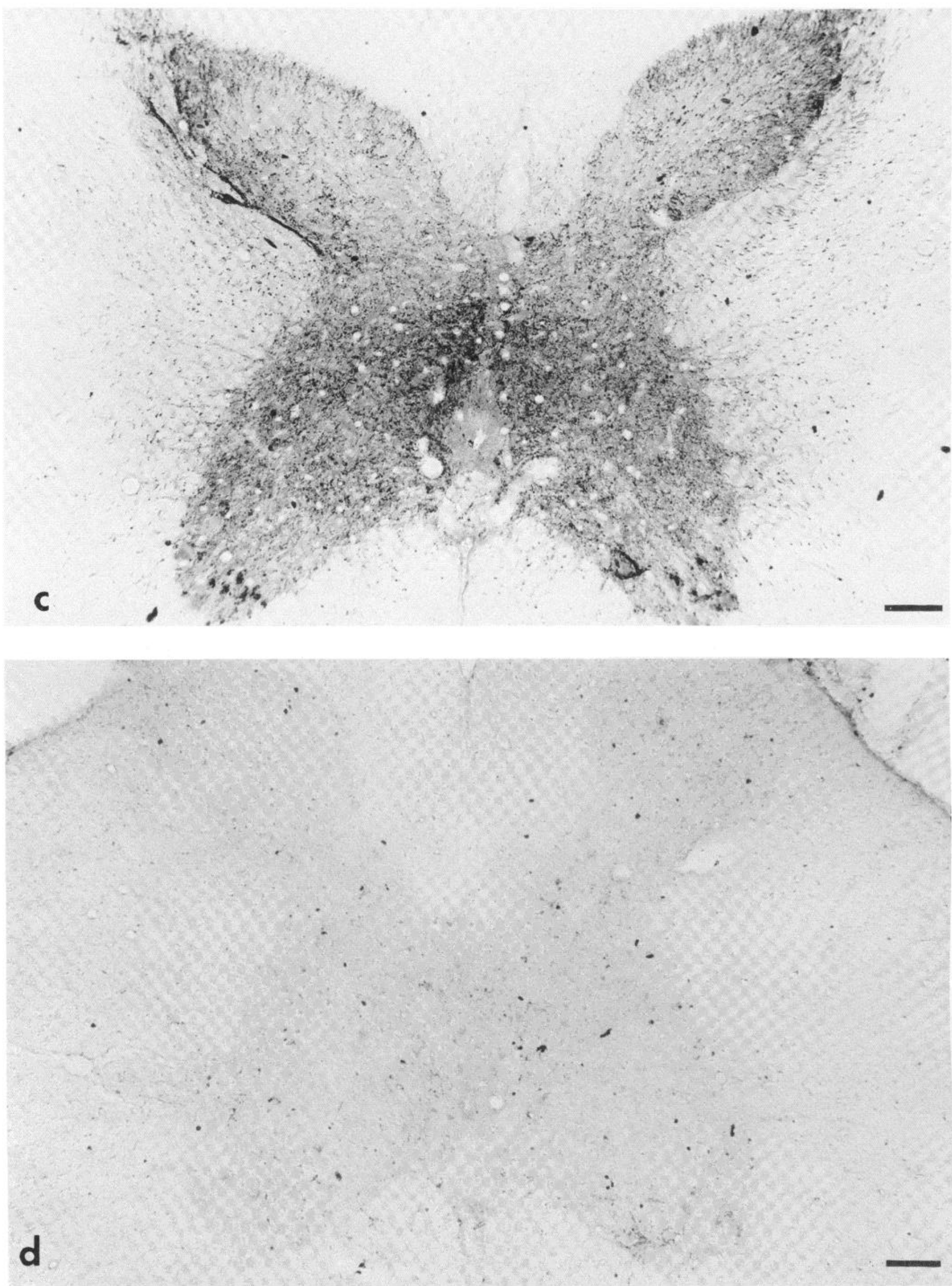

Figure 7, $c$ and $d$ 

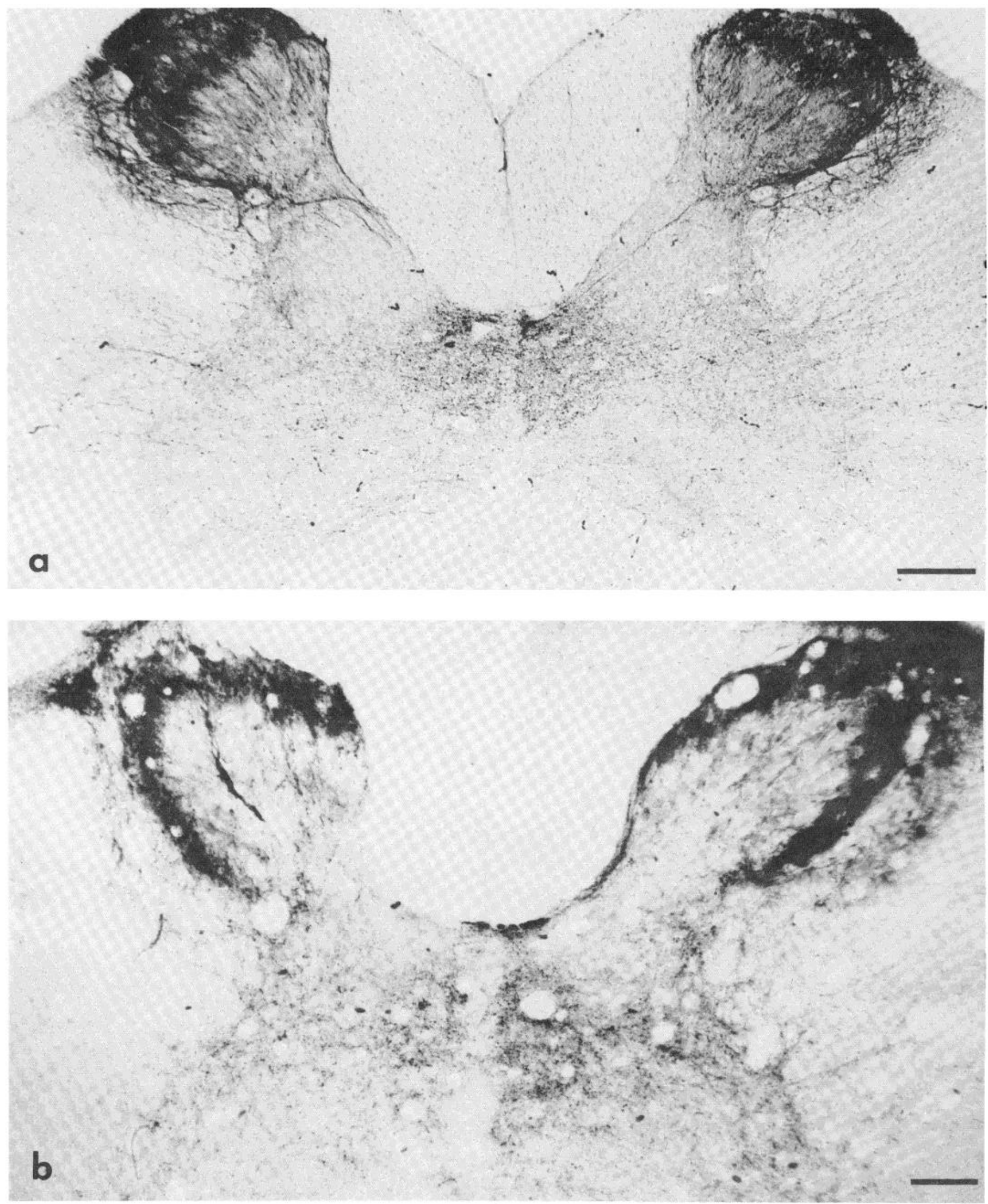

Figure 8. SPLI in thoracic spinal segments isolated by two complete transections or two ipsilateral hemisections. $a$, SPLI in T4 following transections at T3 and T5. SPLI appears normal in the dorsal horn but is diminished in SPN neuropil. $b$, SPLI in thoracic spinal segment isolated by two ipsilateral hemisections on the left side of the spinal cord. Depletion is seen in the dorsal root entry zone, tract of Lissauer, and SPN neuropil ipsilateral (left side) to hemisections. The SP-positive fiber tract immediately lateral to the dorsal horn is also depleted on the lesioned side. PAP method. Calibration bars $=100 \mu \mathrm{m}$. 
contributing any SPLI terminations within the SPN cell column.

Intraspinal SP projections to SPNs. Detectable depletion of SPLI within the SPN cell column was found only following complete transections of thoracic spinal cord or when hemisections and transections isolating thoracic spinal cord segments were performed. Even in these cases, appreciable SPLI staining remained, thereby suggesting that the majority of SP-containing terminations within the SPN cell column are terminals of cells located within the spinal gray. There are two general organizational circuits that potentially contribute such afferent SP input: local segmental and longer intersegmental (e.g., propriospinal) pathways. The two possibilities are not necessarily mutually exclusive.

The presence of local circuitry is supported by two observations. First, complete transection of thoracic spinal cord depleted SPLI in the SPN neuropil only 2 to $3 \mathrm{~mm}$ rostral and caudal to the lesion; at greater distances, normal patterns of SPLI were evident. Second, in those cases where one or two thoracic spinal cord segments were totally isolated, SPLI was still present surrounding SPNs. While it is not possible to state categorically the specific location(s) of spinal neurons which give rise to SPLI-containing fibers projecting to SPNs, it is possible that the confluence of SPLI fibers located laterally along the edge of the dorsal horn forms part of the circuit. Like SPLI in the SPN cell column, this fiber bundle is only disrupted very close to sites of transection or hemisection. Preliminary autoradiographic data show apparent labeling of this fiber bundle following ${ }^{3} \mathrm{H}$-amino acid injections into the dorsal horn of thoracic spinal cord (B. M. Davis and J. B. Cabot, unpublished observations). It is also noteworthy that this fiber tract is not labeled when ${ }^{3} \mathrm{H}$-amino acids are injected into the medullary/caudal pontine raphe complex (Cabot et al., 1982; Cabot and Bogan, 1982).

The presence of intersegmental SP-containing pathways is suggested by several of the findings, but most notably by the appearance of SP-positive granules in the lateral and dorsolateral fasciculi rostral and caudal to thoracic transections and isolated thoracic spinal segments. This observation was repeatable even when a cervical hemisection was performed 14 days prior to lesioning thoracic cord. Staining in these fibers and granules is similar to that observed in the proximal end of axotomized or ligated catecholaminergic axons. Accumulation of catecholamine following lesioning of catecholaminergic axons had been interpreted to be the result of catecholamines "welling-up" in the stump of the proximal end of the axon. SPLI has been previously shown to accumulate in the proximal end of cut dorsal root ganglion fibers (Jessel et al., 1979), and, assuming a similar process is occurring in the present experiments, the SPLI-containing granules and fibers observed following a lesion may represent the proximal end of SP-containing axons.

The location of granules and fibers would be consistent with "long propriospinal" systems ascending and descending in the spinal cord (Moelnaars and Kuypers, 1978). In contrast, axonal accumulation of 5-HTLI in the lateral and dorsolateral fasciculi was only seen rostral to transections. This region of the spinal white matter is known to contain descending bulbospinal 5HT axons (Cabot et al., 1982); hence, the distribution of 5-HTimmunoreactive granules is consistent with the known anatomy of descending brainstem 5-HT systems. The extent to which the intersegmental SPLI pathways contribute to the staining surrounding the SPN is difficult to deduce. It is possible that they represent an unrelated system(s) and that the depletion of SPLI in isolated segments of the spinal cord is due to interruption of separate, local intraspinal circuitry.

In conclusion, the results demonstrate that the majority of SPLI in the SPN neuropil is of intraspinal origin. In contrast, the majority (if not all) of 5-HTLI around SPNs is of supraspinal origin. The SP axons that synapse on the SPNs may be traveling in the lateral and dorsolateral fasciculi and/or in other fiber bundles, such as the prominent tract along the lateral margin of the dorsal horn.

\section{References}

Barber, R. D., J. E. Vaughn, J. R. Slemmon, P. M. Salavaterra, E. Roberts, and S. E. Leeman (1979) The origin, distribution and synaptic relationships of substance $\mathrm{P}$ axons in rat spinal cord. J. Comp. Neurol. 184: 333-352.

Beacham, W. S., and E. R. Perl (1964) Background and reflex discharge of sympathetic preganglionic neurons in the spinal cat. J. Physiol. (Lond.) 172: 400-416.

Beacham, W. S., and E. R. Perl (1965) Characteristics of spinal sympathetic reflex. J. Physiol. (Lond.) 173: 431-448.

Bowker, R. M., H. W. M. Steinbusch, and J. D. Coulter (1981) Serotonergic and peptidergic projections to spinal cord demonstrated by a combined retrograde $\mathrm{HRP}$ histochemical and immunocytochemical staining method. Brain Res. 211: 412 417.

Bowker, R. M., K. N. Westlund, M. C. Sullivan, S. F. Wilber, and J. D. Coulter (1982) Transmitters of raphe-spinal complex: Immunocytochemical studies. Peptides 3: 291-298.

Brooks, C. M. (1933) Reflex activation of the sympathetic system in spinal cat. Am. J. Physiol. 106: 251-266.

Brooks, C. M. (1935) The reaction of chronic spinal animals to hemorrhage. Am. J. Physiol. 114: 30-39.

Cabot, J. B. and N. Bogan (1982) Topography of raphe-spinal pathways. Soc. Neurosci. Abstr. 8: 556.

Cabot, J. B., A. Reiner, and N. Bogan (1982) Avian bulbospinal pathways: Anterograde and retrograde studies of cells of origin, funicular trajectories and laminar terminations. Prog. Brain Res. 57: 79-108.

Cabot, J. B., N. Bogan, and B. M. Davis (1983) Characterization of chemically definable inputs to sympathetic preganglionic neurons: Monoamines, substance P and oxytocin. In Frontiers of Engineering and Computing in Health Care, 5th Annual Conference, G. Gerhard and W. Miller, eds. pp. 66-77, IEEE, New York.

Carlsson, A., B. Falck, K. Fuxe, and N. A. Hillarp (1964) Cellular localization of monoamines in the spinal cord. Acta Physiol. Scand. 60: 112-119.

Chan-Palay, V. (1979) Combined immunohistochemistry and autoradiography after in vivo injections of monoclonal antibody to substance $\mathbf{P}$ and ${ }^{3} \mathrm{H}$-serotonin: Coexistence of two putative transmitters in single raphe cells and fiber plexuses. Anat. Embryol. 156: 241245.

Chan-Palay, V., G. Jonsson, and S. L. Palay (1978) Serotonin and substance $\mathbf{P}$ coexist in neurons of the rat central nervous system. Proc. Natl. Acad. Sci. U. S. A. 75: 1582-1586.

Dahlstrom, A., and K. Fuxe (1964) Evidence for the existence of monoamine-containing neurons in the central nervous system. I. Demonstration of monoamines in cell bodies of brain stem neurons. Acta Physiol. Scand. 62 (Suppl. 232): 1-55.

Dahlstrom, A., and K. Fuxe (1965) Evidence for the existence of monoamine-containing neurons in the central nervous system. II. Experimentally induced changes in the intraneuronal amine levels of bulbospinal neuron systems. Acta. Physiol. Scand. 64 (Suppl. 247): 1-36.

de Lanerolle, N. C., and C. C. LaMotte (1982) The human spinal cord: Substance $\mathrm{P}$ and methionine-enkephalin immunoreactivity. J. Neurosci. 2: 1369-1386.

Ditirro, F. J., R. H. Ho, and G. F. Martin (1981) Immunohistochemical localization of substance $P$, somatostatin and methionine-enkephalin in the spinal cord and dorsal root ganglia of the North American opossum, Didelphis virginia. J. Comp. Neurol. 198: 351363.

Gilbert, R. F. T., P. C. Emson, S. P. Hunt, G. W. Bennett, C. A. Marsden, B. E. B. Sandberg, H. W. M. Steinbusch, and A. A. J. Verhofstad (1982) The effects of monoamine neurotoxins on peptides in the rat spinal cord. Neuroscience 7: 69-87.

Helke, C. J., J. J. Neil, V. J. Massari, and A. D. Loewy (1982) Substance $P$ neurons project from the ventral medulla to the intermediolateral cell column and the ventral horn in the rat. Brain Res. 243: 147152.

Hokfelt, T., J. O., Kellerth, G. Nilsson, and B. Pernow (1975) Substance $P$ : Localization in the central nervous system and in some primary 
sensory neurons. Science 190: 889-890.

Huber, J. F. (1936) Nerve roots and nuclear groups in spinal cord of the pigeon. J. Comp. Neurol. 65: 43-91.

Jessel, T. M., A. Tsunoo, T. Kandzawa, and M. Otsuka (1979) Substance P: Depletion in the dorsal horn of rat spinal cord after section of the peripheral process of primary sensory neurons. Brain Res. 168: $247-259$.

Johansson, O., T. Hokfelt, B. Pernow, S. L. Jeffcoate, N. White, H. W. M. Steinbusch, A. A. J. Verhofstad, P. C. Emson, and E. Spindel (1981) Immunocytochemical support for three putative transmitters in one neuron: Coexistence of 5-hydroxytryptamine, substance $\mathrm{P}$ and thyrotropin releasing hormone-like immunoreactivity in medullary neurons projecting to spinal cord. Neuroscience $6: 1857-1881$

Kanazawa, I., D. Sutoo, I. Oshima, and S. Sato (1979) Effect of transection on choline acetyltransferase, thyrotropin releasing hor mone and substance $\mathrm{P}$ in the cat cervical spinal cord. Neurosci. Lett. 13: $325-330$.

Kluver, H., and E. Barrera (1953) A method for the combined staining of cells and fibers in the nervous system. J. Neuropathol. Exp. Neurol. 12: 400-403.

Leonard, R. B. and D. H. Cohen (1975a) A cytoarchitectonic analysis of the spinal cord of the pigeon (Columba livia). J. Comp. Neurol. 163: $159-180$.

Leonard, R. B., and D. H. Cohen (1975b) Spinal terminal fields of dorsal root fibers in the pigeon (Columba livia). J. Comp. Neurol. 163: $181-192$.

Light, A. R., and E. R. Perl (1977) Differential termination of large diameter and small-diameter primary afferent fibers in the spinal dorsal gray matter as indicated by labelling with horseradish peroxidase. Neurosci. Lett. 6: 59-63.

Light, A. R., and E. R. Perl (1979) Reexamination of the dorsal root projection to the spinal dorsal horn including observations on the differential terminations of coarse and fine fibers. J. Comp. Neurol. 186: $117-132$.

Ljungdahl, A., T. Hokfelt, and G. Nilsson (1978) Distribution of substance P-like immunoreactivity in the central nervous system of the rat. I. Cell bodies and nerve terminals. Neuroscience 3: 861-944

Loewy, A. D., S. McKellar, and C. B. Saper (1979) Direct projections from the A5 catecholamine cell group to the intermediolateral cell column. Brain Res. 174: 309-315

Loewy, A. D., and S. McKellar (1981) Serotonergic projections from the ventral medulla to the intermediolateral cell column in the rat. Brain Res. 211: 196-152.

Loewy, A. D., and J. J. Neil (1981) The role of descending monoaminergic systems in central control of blood pressure. Fed. Proc. 40 : 56-63.

Martin, G. F., A. O. Humbertson, C. C. Laxson, and W. M. Panneton (1979) Evidence for direct bulbospinal projections to lamina IX, X and intermediolateral cell column. Studies using axonal transport techniques in the North American opossum. Brain Res. 170: 165 171.

Martin, G. F., T. Cabana, A. O. Humbertson, Jr., C. C. Laxson, and W. M. Pameton (1981) Spinal projections from the medullary reticular formation of the North American opposum: Evidence for connectional heterogeneity. J. Comp. Neurol. 196: 663-682.
McKelvy, J. F., B. M. Davis, J. E. Krause, and J. B. Cabot (1982) Contribution of bulbospinal and intraspinal pathways to substance P-like immunoreactivity in the thoracic spinal cord. Soc. Neurosci. Abstr. 8: 584.

McLean, I. W., and P. K. Nakane (1974) Periodate-lysine-paraformaldehyde fixative: A new fixative for immunoelectron microscopy. J. Histochem. Cytochem. 22: 1077-1083.

Moelnaars, I., and H. G. J. M. Kuypers (1978) Cells of origin of propriospinal fibers and of fibers ascending to supraspinal levels: $A$ horseradish peroxidase study in cat and rhesus monkey. Brain Res. 152: 429-450.

Nilaver, G., E. A. Zimmerman, J. Wikins, J. Micheals, D. Hoffman, and A. J. Silverman (1980) Magnocellular hypothalamic projections to the lower brain stem and spinal cord of the rat. Immunocytochemical evidence for predominance of oxytocin-neurophysin system compared to vasopressin-neurophysin system. Neuroendocrinology 30 . $150-158$.

Petras, J. M., and J. F. Cummings (1972) Autonomic neurons in the spinal cord of the rhesus monkey: A correlation of the findings of cytoarchitectonic and sympathectomy with fiber degeneration following dorsal rhizotomy. J. Comp. Neurol. 146: 189-218.

Reis, D. J. (1972) Central mechanisms governing the circulation with particular reference to the lower brainstem and cerebellum. In Neural and Psychological Mechanisms in Cardiovascular Disease, A. Zanchette ed., pp. 255-280, Casa Editrice "Il Ponte," Milan.

Ross, C. A., D. M. Armstrong, D. A. Ruggiero, V. M. Pickel, T. A. Joh and D. J. Reis (1981) Adrenalin neurons in the rostral ventrolateral medulla innervate thoracic spinal cord: A combined immunocytochemical and retrograde transport demonstration. Neurosci. Lett. 25: $257-262$

Saper, C. B., A. D. Loewy, L. W. Swanson, and W. M. Cowan (1976) Direct hypothalamo-autonomic connections. Brain Res. 117: 305312.

Schipper, J., and F. J. H. Tilders (1983) A new technique for studying specificity of immunocytochemical procedures: Specificity of serotonin immunostaining. J. Histochem. Cytochem. 31: 12-18.

Steinbusch, H. W. M. (1981) Distribution of serotonin-immunoreactivity in the central nervous system of the rat-cell bodies and terminals. Neuroscience 4: 557-618.

Sternberger, L. (1979) Immunohistochemistry, John Wiley \& Sons, New York.

Swanson, L. W. (1977) Immunohistochemical evidence for a neurophysin containing autonomic pathway arising in the paraventricular nucleus of the hypothalamus. Brain Res. 128: 346-353.

Takahashi, T., and M. Otsuka (1975) Regional distribution of substance $P$ in the spinal cord and nerve roots of the cat and the effects of dorsal section. Brain Res. 87: 1-11.

Tessler, A., E. Glazer, R. Artymyshyn, M. Murray, and M. E. Goldberger (1980) Recovery of substance $P$ in the cat spinal cord after unilateral lumbosacral deafferentation. Brain Res. 191: 459-470.

Westlund, K. N., and J. D. Coulter (1980) Descending projections of the locus coeruleus and subcoeruleus/medial parabrachial nuclei in monkey: Axonal transport studies and dopamine-beta-hydroxylase immunocytochemistry. Brain Res. Rev. 2: 235-264. 